\title{
IMPAIRMENT OF PULMONARY FUNCTION AND CHANGES IN THE RIGHT CARDIAC STRUCTURE OF PNEUMOCONIOTIC COAL WORKERS IN CHINA
}

\author{
LU-QIN BIAN ${ }^{1}$, YUE ZHANG ${ }^{1}$, RONG JIANG ${ }^{2}$, and LING MA0 ${ }^{1}$ \\ ${ }^{1}$ Shanghai Pulmonary Hospital, Shanghai, China \\ Tongji University School of Medicine, Department of Pneumoconiosis \\ ${ }^{2}$ Shanghai Pulmonary Hospital, Shanghai, China \\ Tongji University School of Medicine, Department of Cardio-Pulmonary Circulation
}

\begin{abstract}
Objectives: Information on the changes of pulmonary function and the right cardiac structure in patients with coal worker's pneumoconiosis in China is very scarce. This study was performed to clarify the changes of pulmonary function and right cardiac structure in patients with coal worker's pneumoconiosis in China. Material and Methods: Pulmonary function, pulmonary artery systolic pressure, and the right cardiac structure were evaluated by spirometry and color Doppler echocardiography. Results: The pulmonary artery systolic pressure of patients with coal worker's pneumoconiosis was increased with disease severity. Patients with coal worker's pneumoconiosis also exhibited an impaired pulmonary function and altered right cardiac structure compared with control subjects. A significant linear correlation of the variables of pulmonary ventilation and diffusion function with the indicators of the right cardiac structure was found in patients with coal worker's pneumoconiosis in China. Conclusions: This study elucidated a deterioration of pulmonary function and right cardiac structure in patients with coal worker's pneumoconiosis in China.
\end{abstract}

Key words:

Coal worker's pneumoconiosis, Pulmonary artery systolic pressure, Pulmonary function, Right cardiac structure

\section{INTRODUCTION}

Coal worker's pneumoconiosis is a systemic disease mainly caused by pulmonary interstitial fibrosis triggered by long-term inhalation of dusts released in industrial processes. The morbidity and mortality of the disease continue to increase. Once coal worker's pneumoconiosis occurs, the patients cannot be cured. Thus, a heavy financial burden is placed not only on patients but also on the society. Coal worker's pneumoconiosis also causes several complications, including respiratory system infection, pneumothorax, pulmonary heart disease, and respiratory failure. Chronic pulmonary heart disease accounts for $25-30 \%$ of these complications and $30-50 \%$ of coal worker's pneumoconiosis cases are fatal in China [1]. With increased demands in China, many patients with shortterm exposure to high coal dust concentrations are susceptible to pulmonary fibrosis and eventually to chronic pulmonary heart disease. Therefore, correct diagnosis and timely treatment of complications are life-saving approaches. In addition, health care systems in China have not generally covered the

Received: May 18, 2014. Accepted: August 10, 2014.

Corresponding author: L-Q. Bian, Shanghai Pulmonary Hospital, Tongji University School of Medicine, Department of Pneumoconiosis, No. 507, Zhengmin Road, 200433, Shanghai, China (e-mail: bianlqsph@gmail.com). 
examinations conducted to evaluate pulmonary functions and right cardiac structure of patients with coal worker's pneumoconiosis. Therefore, information on the changes of pulmonary function and the right cardiac structure in patients with coal worker's pneumoconiosis in present-day China is very limited. To address these issues, in this study we assessed the patterns of abnormal spirometry and impairment of the right cardiac structure of the Chinese coal workers.

\section{MATERIAL AND METHODS}

\section{Study population}

A total of 138 patients with coal worker's pneumoconiosis and 100 exposure control subjects were recruited from the Department of Pneumoconiosis at the Shanghai Pulmonary Hospital of Tongii University School of Medicine between January 2010 and December 2012. All of them were underground coal miners and spent their entire working career within the mining company. Occupational health monitoring data, including physical examination results and chest radiograph, were obtained every year.

Patients were subjected to high-kilovolt chest X-rays to confirm the diagnosis of coal worker's pneumoconiosis in accordance with the China National Diagnostic Criteria for Pneumoconiosis (GBZ 70-2002) [2], which is the same as the International Labor Organization Classification of Pneumoconiosis [3]. Disease stage was classified according to size, profusion, and distribution range of opacities observed in chest X-ray [2].

Stage I was defined as opacity profusion of level 1, distribution range of at least 2 lung fields or opacity profusion of level 1 , distribution range of more than 4 lung fields or opacity profusion of level 2, distribution range of 4 lung fields. Stage II was defined as opacity profusion of level 2, distribution range of more than 4 lung fields or opacity profusion of level 3 , distribution range of 4 lung fields or opacity profusion of level 3 , distribution range of more than 4 lung fields. Stage III was defined as large opacity having the largest dimension exceeding $20 \mathrm{~mm}$ and the smallest dimension exceeding $10 \mathrm{~mm}$ or 1 large opacity exceeding the equivalent area of right upper zone of lung or several large opacities which, when combined, exceed the equivalent area of right upper zone of lung. Exposure control subjects were defined as individuals without coal worker's pneumoconiosis but with coal dust exposure history. The subjects in each group were then balanced in terms of gender, age, dust exposure time and smoking status. All of the subjects did not exhibit evidence of tuberculosis, autoimmune diseases, pneumonia, other interstitial lung diseases, and predominantly obstructive cardiopulmonary diseases caused by other disorders. In addition, 100 healthy controls in the healthy screening program of our hospital were included as a negative control matched for gender, age, and smoking status. Each subject was instructed to complete an epidemiological questionnaire that required individual information, including occupational history, smoking habits, and others. The questionnaire was administered face-to-face by interviewers who were blinded regarding the case or control status of subjects.

\section{Pulmonary function test}

Spirometry, lung volumes, and diffusing capacity measurements were performed in accordance with ATS guidelines [4-6]. Spirometry values, lung volumes, and diffusing capacity were presented as percentages of the predicted values as suggested previously [7,8]. SensorMedics (Northridge, CA) Vmax 22 systems comprising a $6200 \mathrm{Au}$ tobox were used to measure lung volumes. The plethysmograph software Vmax Legacy (Viasys, Yorba Linda, CA) was used. Total airway resistance was measured according to previously described methods [9].

\section{Assessment of pulmonary arterial systolic pressure (PASP) and right cardiac structure by echocardiography} Pulmonary arterial systolic pressure (PASP) was assessed by the staff cardiologists in our institution. The following protocol was used to assess PASP: 
- each patient was placed in the left lateral decubitus position,

- color flow Doppler imaging was used to identify and guide the alignment of the cursor with the tricuspid regurgitant jet,

- continuous-wave Doppler was used to assess tricuspid regurgitation velocity from different views and determine the peak velocity (v),

- transtricuspid pressure gradient was calculated using the modified Bernoulli equation $\left(4 \mathrm{v}^{2}\right)$ [10],

- right atrial pressure was evaluated from the respiratory variation in the diameter of the inferior vena cava (values estimated as 5,10 , or $15 \mathrm{~mm} \mathrm{Hg}$ ),

- PASP was calculated by adding the transtricuspid pressure gradient to the atrial pressure estimate.

The following cardiac morphological characteristics and function indicators were determined: pulmonary artery diameter (PA); right atrial diameter (RA); and right ventricular diameter (RV). Tricuspid annular plane systolic excursion (TAPSE) and tricuspid valve systolic peak velocity $(\mathrm{Sm})$ were determined as previously reported [11]. Pulmonary artery hypertension was defined as 2 consecutive pulmonary arterial systolic pressure (PASP) values $\geq 40 \mathrm{~mm} \mathrm{Hg}$ revealed by echocardiography [12].

\section{Ethics}

This study was conducted in accordance with the Helsinki Declaration of 1975 and approved by the Ethics Committee of Tongji University. Informed consent was obtained from all of the participants.

\section{Statistical analysis}

Numerical values were expressed as mean \pm standard deviation $(\mathrm{M} \pm \mathrm{SD})$. Student's t-test or Mann-Whitney U test was used to compare the numerical values when appropriate. $\mathrm{Chi}^{2}$ analysis was applied to compare groups for categorical variables. The relation of the prevalence and stage of coal worker's pneumoconiosis with the prevalence of pulmonary artery hypertension was estimated by computing odds ratio (OR) and 95\% confidence interval (CI) by logistic regression analysis; values were adjusted for possible confounders. Age, dust exposure, and smoking amount cut-off values used for the stratified analysis were according to the median values of the recruited patients and control subjects. Spearman correlation analysis was conducted to determine the correlation between variables. A trend analysis was also performed as previously described [13]. Statistical tests were 2-sided at a significance level of 0.05 and analyzed using SPSS 17.0 (SPSS, Chicago, IL, USA).

\section{RESULTS}

\section{Characteristics of the study subjects}

The demographic and clinical data of the subjects are summarized in Table 1. No significant differences were observed among the cases and the 2 groups of control subjects in terms of gender and age distribution. There was no significant difference in terms of dust exposure time among the cases and the exposure control subjects. The distribution of the smoking status of the cases and the 2 groups of control subjects was similar. No significant differences were observed among the cases and the 2 controls in terms of the distribution of the smoking amount (pack-years). The coal worker's pneumoconiosis stages I-III of the cases were $63.8 \%, 20.3 \%$, and $15.9 \%$ respectively.

\section{Changes in the PASP and the right cardiac structure} The PASP of patients with coal worker's pneumoconiosis was increased with the severity of the disease. Patients with stage II and III coal worker's pneumoconiosis exhibited a significantly higher PASP than those in stage I and the control subjects ( $p<0.01)$. The PASP of patients in stage III was higher than that of patients in stage II $(\mathrm{p}<0.01)$. Patients in stage III exhibited the widest pulmonary artery (PA) and right atrium among all groups $(\mathrm{p}<0.05)$. In addition, all of the patients with coal 
Table 1. Demographic characteristics and selected variables among the groups

\begin{tabular}{|c|c|c|c|c|c|c|}
\hline \multirow{2}{*}{ Variable } & \multirow{2}{*}{$\begin{array}{c}\text { Healthy } \\
\text { group }\end{array}$} & \multirow{2}{*}{$\begin{array}{l}\text { Exposure } \\
\text { group }\end{array}$} & \multicolumn{3}{|c|}{ Coal worker's pneumoconiosis group } & \multirow{2}{*}{$\mathrm{p}$} \\
\hline & & & stage I & stage II & stage III & \\
\hline Study group $[\mathrm{n}(\%)]$ & $100(100)$ & $100(100)$ & $88(63.8)$ & $28(20.3)$ & $22(15.9)$ & \\
\hline Gender (male/female) (n) & $62 / 38$ & $60 / 40$ & $56 / 35$ & $20 / 8$ & $17 / 5$ & n.s. \\
\hline Age (years) $(\mathrm{M} \pm \mathrm{SD})$ & $65.2 \pm 9.8$ & $66.1 \pm 9.2$ & $67.1 \pm 11.2$ & $65.4 \pm 10.5$ & $63.1 \pm 14.5$ & n.s. \\
\hline Exposure time (years) $(\mathrm{M} \pm \mathrm{SD})$ & & $23.2 \pm 5.3$ & $24.2 \pm 5.4$ & $25.2 \pm 6.1$ & $24.4 \pm 6.3$ & n.s. \\
\hline Smoking $[\mathrm{n}(\%)]$ & & & & & & n.s. \\
\hline yes & $58(58.0)$ & $57(57.0)$ & $52(59.0)$ & $15(53.6)$ & $12(54.5)$ & \\
\hline no & $42(42.0)$ & $43(43.0)$ & $36(41.0)$ & $13(46.4)$ & $10(45.4)$ & \\
\hline Pack-years smoked [n (\%)] & & & & & & n.s. \\
\hline$<20$ & $63(63.0)$ & $63(63.0)$ & $58(65.9)$ & $19(67.9)$ & $15(68.1)$ & \\
\hline$\geq 20$ & $37(37.0)$ & $37(37.0)$ & $30(34.1)$ & $9(32.1)$ & $7(31.9)$ & \\
\hline
\end{tabular}

M - mean; SD - standard deviation; n.s. - not statistically significant.

Table 2. The changes of pulmonary artery systolic pressure and alterations of the right cardiac structure among the groups

\begin{tabular}{|c|c|c|c|c|c|}
\hline \multirow[b]{2}{*}{ Variable } & \multirow[b]{2}{*}{$\begin{array}{l}\text { Healthy group } \\
\quad(\mathrm{N}=100)\end{array}$} & \multirow[b]{2}{*}{$\begin{array}{l}\text { Exposure group } \\
\qquad(\mathrm{N}=100)\end{array}$} & \multicolumn{3}{|c|}{ Coal worker's pneumoconiosis group } \\
\hline & & & $\begin{array}{l}\text { stage I } \\
(\mathrm{N}=88)\end{array}$ & $\begin{array}{l}\text { stage II } \\
(\mathrm{N}=28)\end{array}$ & $\begin{array}{l}\text { stage III } \\
(\mathrm{N}=22)\end{array}$ \\
\hline $\mathrm{PASP}(\mathrm{mm} \mathrm{Hg})(\mathrm{M} \pm \mathrm{SD})$ & $18.13 \pm 8.56$ & $20.55 \pm 9.43$ & $33.43 \pm 10.37$ & $42.95 \pm 15.33^{* *, \# \#}$ & $53.06 \pm 29.49^{* *, \# \#, \neq \neq}$ \\
\hline PA diameter $(\mathrm{mm})(\mathrm{M} \pm \mathrm{SD})$ & $24.71 \pm 3.07$ & $23.89 \pm 4.56$ & $23.08 \pm 4.43$ & $23.75 \pm 6.14$ & $27.06 \pm 5.99^{*, \#, \neq}$ \\
\hline $\begin{array}{l}\text { Right atrial diameter }(\mathrm{mm}) \\
\quad(\mathrm{M} \pm \mathrm{SD})\end{array}$ & $33.10 \pm 5.00$ & $34.33 \pm 7.69$ & $35.49 \pm 5.65$ & $35.53 \pm 5.22$ & $38.10 \pm 8.70^{*, \#,+}$ \\
\hline $\begin{array}{l}\text { Right ventricular diameter } \\
\qquad(\mathrm{mm})(\mathrm{M} \pm \mathrm{SD})\end{array}$ & $23.80 \pm 8.80$ & $24.32 \pm 5.73$ & $31.06 \pm 5.73^{* *}$ & $32.05 \pm 6.91^{* *}$ & $32.27 \pm 6.42^{* *}$ \\
\hline $\operatorname{TAPSE}(\mathrm{mm})(\mathrm{M} \pm \mathrm{SD})$ & $20.28 \pm 4.18$ & $22.06 \pm 4.59$ & $20.10 \pm 3.52$ & $18.70 \pm 3.02$ & $19.25 \pm 2.59$ \\
\hline $\begin{array}{l}\text { Tricuspid valve } \mathrm{Sm}(\mathrm{cm} / \mathrm{s}) \\
(\mathrm{M} \pm \mathrm{SD})\end{array}$ & $12.85 \pm 3.93$ & $12.15 \pm 2.22$ & $12.81 \pm 2.78$ & $10.21 \pm 1.47^{* *, \# \#}$ & $9.86 \pm 1.14^{* *, \# \#}$ \\
\hline $\begin{array}{l}\text { Prevalence of pulmonary } \\
\text { artery hypertension }(\%)\end{array}$ & 0 & 0 & $12.5^{* *}$ & $54.7^{* *, \# \#}$ & $68.2^{* *, \# \#, \neq \neq}$ \\
\hline
\end{tabular}

PASP - pulmonary artery systolic pressure; PA - pulmonary artery; TAPSE - tricuspid annular plane systolic excursion; Sm - systolic peak velocity. $\mathrm{M}, \mathrm{SD}$ - as in Table 1.

Compared to healthy and exposure group: $* \mathrm{p}<0.05$, ${ }^{*} \mathrm{p}<0.01$.

Compared to stage I coal worker's pneumoconiosis: ${ }^{\#} \mathrm{p}<0.05,{ }^{\# \#} \mathrm{p}<0.01$.

Compared to stage II coal worker's pneumoconiosis: ${ }^{\ddagger} \mathrm{p}<0.05,{ }^{\ddagger \neq} \mathrm{p}<0.01$.

worker's pneumoconiosis showed a dramatically broadened right ventricle $(\mathrm{p}<0.01)$. However, patients exhibiting different disease stages showed similar right ventricular diameter. Furthermore, patients in stage II and III exhibited a significantly reduced tricuspid valve systolic peak velocity $(\mathrm{Sm})$ compared with those in stage I and control subjects $(\mathrm{p}<0.01)$, while the difference between stages II and III was not significant (Table 2). 


\section{Changes in the variables}

\section{of pulmonary function among groups}

Patients with stage II and III coal worker's pneumoconiosis exhibited a significantly reduced $\mathrm{PaO}_{2}$, forced expiratory volume in $1 \mathrm{~s} /$ forced vital capacity ratio $\left(\mathrm{FEV}_{1} / \mathrm{FVC}\right)$, diffusion capacity of carbon monoxide (DLCO) and increased residual volume (RV), residual volume/total lung capacity ratio (RV/TLC), and total airway resistance (Rtot and Reff) compared with those in stage I and control subjects ( $p<0.05)$. Patients in stage III exhibited the same pattern for these variables compared with those in stage II. In addition, patients in stage III exhibited the lowest forced expiratory volume in 1 second $\left(\mathrm{FEV}_{1}\right)$ and diffusion capacity of carbon monoxide/alveolar volume ratio (DLCO/VA) compared with the patients in stages I and II and control subjects $(\mathrm{p}<0.05)$. Partial pressure of carbon monoxide in the arterial blood $\left(\mathrm{PaCO}_{2}\right)$ did not differ among the groups (Table 3).

\section{Relation of the prevalence and stage}

of coal worker's pneumoconiosis to the prevalence of pulmonary artery hypertension

Pulmonary artery hypertension was defined as 2 consecutive pulmonary arterial systolic pressure (PASP) values $\geq 40 \mathrm{~mm} \mathrm{Hg}$ determined by echocardiography [12]. The prevalence of pulmonary artery hypertension increased with the onset and severity of the disease. The prevalence rates of pulmonary artery hypertension were $0 \%, 0 \%, 12.5 \%, 54.7 \%$, and $68.2 \%$ in healthy, exposure, stage I, stage II, and stage III coal worker's pneumoconiosis groups, respectively $\left(\mathrm{p}_{\text {trend }}<0.001\right)$ (Figure 1, Table 2).

In a multivariate regression model, the following parameters were adjusted: gender; age ( $\geq 55$ or $<55$ years); dust

Table 3. The changes of pulmonary function among the groups

\begin{tabular}{|c|c|c|c|c|c|}
\hline \multirow{2}{*}{ Variable } & \multirow{2}{*}{$\begin{array}{l}\text { Healthy group } \\
\qquad(\mathrm{N}=100) \\
(\mathrm{M} \pm \mathrm{SD})\end{array}$} & \multirow{2}{*}{$\begin{array}{l}\text { Exposure group } \\
\qquad(\mathrm{N}=100) \\
(\mathrm{M} \pm \mathrm{SD})\end{array}$} & \multicolumn{3}{|c|}{$\begin{array}{l}\text { Coal worker's pneumoconiosis group } \\
\qquad(\mathrm{M} \pm \mathrm{SD})\end{array}$} \\
\hline & & & $\begin{array}{c}\text { stage I } \\
(\mathrm{N}=88)\end{array}$ & $\begin{array}{c}\text { stage II } \\
(\mathrm{N}=28)\end{array}$ & $\begin{array}{l}\text { stage III } \\
(\mathrm{N}=22)\end{array}$ \\
\hline $\mathrm{PaO}_{2}(\mathrm{~mm} \mathrm{Hg})$ & $98.88 \pm 9.07$ & $97.98 \pm 5.78$ & $94.57 \pm 11.84$ & $82.00 \pm 3.46^{* * * *}$ & $76.75 \pm 8.02^{*, * *, \#}$ \\
\hline $\mathrm{PaCO}_{2}(\mathrm{~mm} \mathrm{Hg})$ & $33.21 \pm 2.39$ & $33.98 \pm 5.66$ & $34.08 \pm 3.90$ & $35.73 \pm 2.32$ & $36.58 \pm 3.81$ \\
\hline $\operatorname{FEV}_{1}(\%)$ & $86.56 \pm 11.02$ & $87.87 \pm 9.08$ & $87.50 \pm 12.04$ & $86.37 \pm 10.06$ & $58.05 \pm 11.13^{*, * *, \#}$ \\
\hline $\mathrm{FEV}_{1} / \mathrm{FVC}$ & $95.43 \pm 10.87$ & $95.31 \pm 9.01$ & $94.04 \pm 11.65$ & $77.90 \pm 11.84^{*, * *}$ & $62.05 \pm 11.18^{*, * *, \#}$ \\
\hline $\mathrm{RV}(\mathrm{l})$ & $1.13 \pm 0.11$ & $1.11 \pm 0.06$ & $1.10 \pm 0.13$ & $1.48 \pm 0.13^{* * * *}$ & $1.67 \pm 0.18^{*, * *, \#}$ \\
\hline $\mathrm{RV} / \mathrm{TLC}$ & $0.23 \pm 0.13$ & $0.26 \pm 0.18$ & $0.26 \pm 0.15$ & $0.35 \pm 0.20^{*, * *}$ & $0.45 \pm 0.19^{*, * *, \#}$ \\
\hline $\mathrm{DLCO}(\mathrm{ml} / \mathrm{min} / \mathrm{mm} \mathrm{Hg})$ & $119.09 \pm 13.33$ & $118.22 \pm 19.46$ & $117.56 \pm 11.27$ & $82.87 \pm 12.75^{*, * *}$ & $76.70 \pm 12.91^{*, * *, \#}$ \\
\hline $\begin{array}{l}\mathrm{DLCO} / \mathrm{VA}(\mathrm{ml} / \mathrm{min} / \\
\mathrm{mm} \mathrm{Hg} / \mathrm{l})\end{array}$ & $112.98 \pm 14.65$ & $109.47 \pm 20.98$ & $111.80 \pm 17.10$ & $94.37 \pm 16.57$ & $81.90 \pm 11.58^{*, * *, \#}$ \\
\hline Rtot $(\mathrm{kPa} / \mathrm{l} \times \mathrm{s})$ & $102.45 \pm 15.89$ & $104.23 \pm 18.12$ & $101.63 \pm 17.03$ & $179.90 \pm 12.40^{* * * *}$ & $197.03 \pm 15.09^{*, * *, \#}$ \\
\hline $\operatorname{Reff}(\mathrm{kPa} / \mathrm{l} \times \mathrm{s})$ & $88.45 \pm 18.32$ & $86.44 \pm 11.22$ & $90.39 \pm 18.64$ & $155.77 \pm 19.41^{* * *}$ & $175.63 \pm 13.98^{*, * *, \#}$ \\
\hline
\end{tabular}

Compare to healthy and exposure group: ${ }^{*} \mathrm{p}<0.05$.

Compare to stage I coal worker's pneumoconiosis: ${ }^{* *} \mathrm{p}<0.05$.

Compare to stage II coal worker's pneumoconiosis: ${ }^{*} \mathrm{p}<0.05$.

$\mathrm{FEV}_{1}$ - forced expiratory volume in $1 \mathrm{~s} ; \mathrm{FVC}$ - forced vital capacity; RV - residual volume; TLC - total lung capacity; DLCO - diffusion capacity for carbon monoxide of the lung; VA - alveolar volume; Rtot, Reff - total airway resistance. M, SD - as in Table 1. 


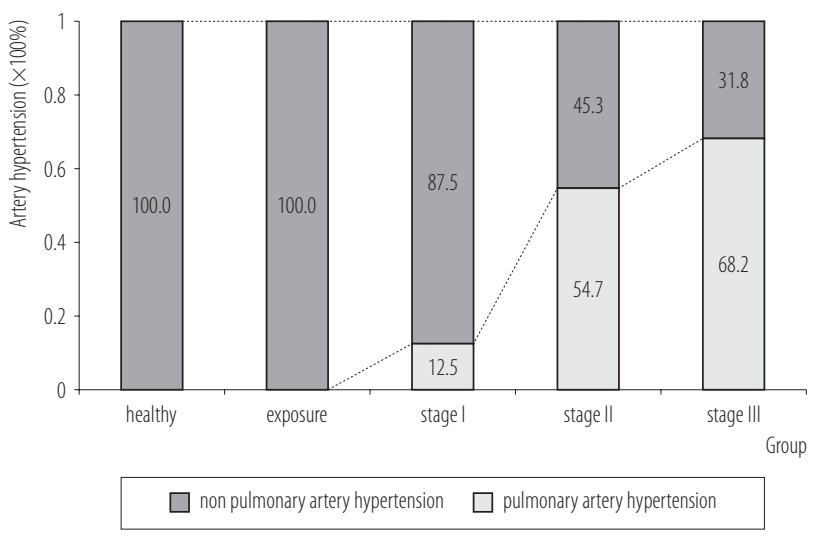

Prevalence of pulmonary artery hypertension increased with the onset and severity of the disease $\left(\mathrm{p}_{\text {trend }}<0.001\right)$.

Fig. 1. Prevalence of pulmonary artery hypertension among the groups

exposure time ( $\geq 22$ or $<22$ years); smoking status (yes or no); pack-years smoked ( $\geq 20$ or $<20$ ). The exposure to dust and the prevalence of coal worker's pneumoconiosis were independently associated with the prevalence of pulmonary artery hypertension. Exposure to dust was also associated with an increased OR of $15 \%$ of the risk of pulmonary artery hypertension $(\mathrm{OR}=1.15,95 \% \mathrm{CI}$ : $1.02-$ $1.91, \mathrm{p}<0.05)$. By comparison, the prevalence of coal worker's pneumoconiosis was associated with an increased OR of $111 \%$ of the risk of pulmonary artery hypertension $(\mathrm{OR}=2.11,95 \%$ CI: $1.21-2.85, \mathrm{p}<0.001)$ compared with healthy control subjects (Table 4). Considering disease stage, we found that stage II was associated with an increased OR of $72 \%$ of the risk of pulmonary artery hypertension ( $\mathrm{OR}=1.71,95 \% \mathrm{CI}: 1.12-2.11, \mathrm{p}<0.001)$. Stage III was associated with an increased OR of $91 \%$ of the risk of pulmonary artery hypertension $(\mathrm{OR}=1.91,95 \% \mathrm{CI}$ : $1.23-$ $2.54, \mathrm{p}<0.001$ ) compared with stage I (Table 4).

\section{Correlations of pulmonary function variables with PASP and the indicators of the right cardiac structure}

Table 5 shows the correlation coefficients between various variables of pulmonary function and indicators of PASP and right cardiac structure of patients with coal worker's pneumoconiosis. We found that $\mathrm{PaO}_{2}$ and $\mathrm{FEV}_{1} / \mathrm{FVC}$ were negatively correlated with PASP, whereas $\mathrm{PaO}_{2}$ and $\mathrm{FEV}_{1}$ were negatively correlated with $\mathrm{PA}$ diameter. We also found that $\mathrm{PaCO}_{2}$ was positively correlated with PA diameter, whereas $\mathrm{PaO}_{2}, \mathrm{DLCO}$, and DLCO/VA were positively correlated with tricuspid valve Sm.

Table 4. Relation of the prevalence or stage of coal worker's pneumoconiosis with the prevalence of pulmonary artery hypertension

\begin{tabular}{|c|c|c|c|c|}
\hline \multirow{2}{*}{ Variable } & \multirow{2}{*}{ Coefficient } & \multicolumn{2}{|c|}{$95 \% \mathrm{CI}^{\sharp}$} & \multirow{2}{*}{$\mathrm{p}^{\#}$} \\
\hline & & lower & upper & \\
\hline \multicolumn{5}{|c|}{ Prevalence of coal worker's pneumoconiosis } \\
\hline healthy & 1.00 & & & \\
\hline exposure & 1.15 & 1.02 & 1.91 & $<0.050$ \\
\hline pneumoconiosis & 2.11 & 1.21 & 2.85 & $<0.001$ \\
\hline \multicolumn{5}{|l|}{ Pneumoconiosis stage } \\
\hline I & 1.00 & & & \\
\hline II & 1.72 & 1.12 & 2.11 & $<0.001$ \\
\hline III & 1.91 & 1.23 & 2.54 & $<0.001$ \\
\hline
\end{tabular}

\# Adjusted for gender, age ( $\geq 55$ or $<55$ years old), dust exposure time ( $\geq 22$ or $<22$ years), smoking status (yes or no) and pack-years smoked $(\geq 20$ or $<20)$.

CI - confidence interval. 
Table 5. Correlations of variables of pulmonary function with pulmonary artery systolic pressure or the indicators of the right cardiac structure in patients with coal worker's pneumoconiosis

\begin{tabular}{|c|c|c|c|c|c|c|c|c|c|c|c|c|}
\hline \multirow{2}{*}{ Variable } & \multicolumn{2}{|c|}{ PASP } & \multicolumn{2}{|c|}{ PA diameter } & \multicolumn{2}{|c|}{$\begin{array}{l}\text { Right atrial } \\
\text { diameter }\end{array}$} & \multicolumn{2}{|c|}{$\begin{array}{l}\text { Right ventricular } \\
\text { diameter }\end{array}$} & \multicolumn{2}{|c|}{ TAPSE } & \multicolumn{2}{|c|}{ Tricuspid valve Sm } \\
\hline & $\mathrm{r}$ & $\mathrm{p}$ & $\mathrm{r}$ & $\mathrm{p}$ & $\mathrm{r}$ & $\mathrm{p}$ & $\mathrm{r}$ & $\mathrm{p}$ & $\mathrm{r}$ & $\mathrm{p}$ & $\mathrm{r}$ & $\mathrm{p}$ \\
\hline$\overline{\mathrm{PaO}_{2}}$ & -0.207 & 0.043 & -0.205 & 0.041 & -0.015 & n.s. & -0.141 & n.s. & -0.026 & n.s. & 0.210 & 0.037 \\
\hline $\mathrm{PaCO}_{2}$ & 0.146 & n.s. & 0.208 & 0.039 & -0.099 & n.s. & -0.110 & n.s. & 0.050 & n.s. & -0.059 & n.s. \\
\hline $\mathrm{FEV}_{1}$ & -0.166 & n.s. & -0.226 & 0.048 & 0.092 & n.s. & -0.064 & n.s. & 0.044 & n.s. & 0.092 & n.s. \\
\hline $\mathrm{FEV}_{1} / \mathrm{FVC}$ & -0.273 & 0.021 & -0.211 & n.s. & 0.009 & n.s. & -0.021 & n.s. & 0.062 & n.s. & -0.136 & n.s. \\
\hline $\mathrm{RV}$ & 0.118 & n.s. & -0.166 & n.s. & -0.003 & n.s. & -0.185 & n.s. & 0.124 & n.s. & 0.219 & n.s. \\
\hline $\mathrm{RV} / \mathrm{TLC}$ & 0.202 & n.s. & -0.024 & n.s. & -0.096 & n.s. & 0.091 & n.s. & 0.050 & n.s. & 0.082 & n.s. \\
\hline DLCO & -0.168 & n.s. & -0.211 & n.s. & 0.117 & n.s. & -0.053 & n.s. & 0.095 & n.s. & 0.333 & 0.005 \\
\hline DLCO/VA & -0.138 & n.s. & -0.006 & n.s. & 0.124 & n.s. & 0.047 & n.s. & 0.073 & n.s. & 0.281 & 0.018 \\
\hline Rtot & 0.154 & n.s. & 0.097 & n.s. & -0.114 & n.s. & 0.060 & n.s. & -0.177 & n.s. & -0.177 & n.s. \\
\hline$\underline{\text { Reff }}$ & 0.157 & n.s. & 0.078 & n.s. & -0.077 & n.s. & -0.043 & n.s. & -0.149 & n.s. & -0.154 & n.s. \\
\hline
\end{tabular}

Abbreviations as in Tables 1-3.

\section{DISCUSSION AND CONCLUSIONS}

The results in the present study revealed that the right cardiac structure and pulmonary function were impaired after other relevant factors, including gender, age, dust exposure time, and tobacco smoking had been considered. The PASP of patients with coal worker's pneumoconiosis was increased with the severity of the disease. The patients also showed a remarkably broadened right ventricle. In addition, a significantly reduced tricuspid valve systolic peak velocity was found in patients with stages II and III. In particular, patients in stage III exhibited the most adverse changes in the right cardiac structure and the highest pulmonary artery systolic pressure. These results may suggest that patients with coal worker's pneumoconiosis, and especially those in the late stage, may exhibit more extensive fibrosis and chronic hypoxia.

The striking tendency to obstruction, reduced diffusion and relative hypoxia in stage III suggested some degree of emphysema. Pulmonary vascular remodeling resulted in PASP, inducing changes to the right cardiac structure.
By contrast, control subjects or patients in early stages showed no, or less pulmonary fibrosis and hypoxia. Therefore, PASP may be maintained in the normal range. In particular, the prevalence of pulmonary artery hypertension was increased with the onset and severity of coal worker's pneumoconiosis. Furthermore, the prevalence or the severity of coal worker's pneumoconiosis was an independent risk factor of pulmonary artery hypertension.

Considering a previous study [14], we found that patients with coal worker's pneumoconiosis exhibited significantly impaired pulmonary functions vs. controls. Some of these functions include poor ventilation and diffusion function as well as high airway resistance. These results also suggested that imbalanced ventilation/perfusion ratio and reduced ventilation capacity and pulmonary ventilation area caused alveolar hypoxia. Increased pulmonary vasodilation, high vascular smooth muscle tension, and small airway obstruction were observed simultaneously when pulmonary hypertension occurred. Diffusion dysfunction is also observed, as small pulmonary vascular occlusion 
causes poor alveolar perfusion $[15,16]$. Our findings were in agreement with Wang's study revealing that the miners with coal workers' pneumoconiosis had lower values of pulmonary function and higher prevalence of respiratory symptoms than did those without it, and a significant relationship was found between coal workers' pneumoconiosis and decrements in FVC and diffusing capacity. In addition, workers with stages II and III diseases showed poorer pulmonary function and more common symptoms $[17,18]$. Furthermore, we determined whether or not pulmonary function variables could be used to predict the impairment of the right cardiac structure. We then performed a correlation analysis and found a significant linear correlation between the variables of pulmonary ventilation/diffusion function and the indicators of the right cardiac structure. Although Fernie et al. revealed a certain right ventricular hypertrophy in coal workers in 1980's, the method for evaluating right cardiac structure was quite different from ours. Necropsy was used in their study. Besides, pulmonary function was not evaluated by Fernie [19]. To the best of our knowledge, this study was the 1st report to investigate the correlation of pulmonary function with the right cardiac structure of patients with coal worker's pneumoconiosis in China.

Although we elucidated the impairment of pulmonary function and right cardiac structure of patients with coal worker's pneumoconiosis, our study was encumbered with several limitations, including small sample size, retrospective design, and being Chinese ethnic-specific. Results from this study could be over-interpreted. Therefore, the confirmation through well-designed, larger prospective studies are needed. Despite the limitations, these findings elucidated a deterioration of pulmonary function and right cardiac structure in patients with coal worker's pneumoconiosis in China and showed the importance of evaluating the pulmonary function and right cardiac structure of patients with coal worker's pneumoconiosis. Further prospective studies are necessary to validate our findings.

\section{REFERENCES}

1. Li HZ, Jiang PR. [Hemorheology of patients with silicosis]. Zhonghua Lao Dong Wei Sheng Zhi Ye Bing Za Zhi. 2007(9);25:563-5. Chinese.

2. Ministry of Health of the People's Republic of China. Diagnostic criteria of pneumoconiosis GBZ 70-2002. Xi'an: Law Press; 2002. p. 1-10.

3. International Labour Office. Guidelines for the use of ILO international classification of radiographs of pneumoconiosis. Geneva: International Labour Office; 2002.

4. Miller MR, Hankinson J, Brusasco V, Burgos F, Casaburi R, Coates A, et al. Standardisation of spirometry. Eur Respir J. 2005;26(2):319-38, http://dx.doi.org/10.1183/09031936.05. 00034805 .

5. Wanger J, Clausen JL, Coates A, Pedersen OF, Brusasco V, Burgos F, et al. Standardisation of the measurement of lung volumes. Eur Respir J. 2005;26(3):511-22, http://dx.doi.org/ 10.1183/09031936.05.00035005.

6. Macintyre N, Crapo RO, Viegi G, Johnson DC, van der Grinten CP, Brusasco V, et al. Standardisation of the singlebreath determination of carbon monoxide uptake in the lung. Eur Respir J. 2005;26(4):720-35, http://dx.doi.org/ 10.1183/09031936.05.00034905.

7. Knudson RJ, Lebowitz MD, Holberg CJ, Burrows B. Changes in the normal maximal expiratory flow-volume curve with growth and aging. Am Rev Respir Dis. 1983;127(6):725-34.

8. Polgar G, Promadhat V. Standard values. In: Pulmonary function testing in children: Techniques and standards. Philadelphia: W.B. Saunders; 1971. p. 87-212.

9. Manzke H, Stadlober E, Schellauf HP. Combined body plethysmographic, spirometric and flow volume reference values for male and female children aged 6 to 16 years obtained from "hospital normals". Eur J Pediatr. 2001;160(5):300-6, http://dx.doi.org/10.1007/s004310100724.

10. Yock PG, Popp RL. Noninvasive estimation of right ventricular systolic pressure by Doppler ultrasound in patients with tricuspid regurgitation. Circulation. 1984;70(4):657-62, http://dx.doi.org/10.1161/01.CIR.70.4.657. 
11. Moceri P, Dimopoulos K, Liodakis E, Germanakis I, Kempny A, Diller GP, et al. Echocardiographic predictors of outcome in Eisenmenger syndrome. Circulation. 2012;126(12):1461-8, http://dx.doi.org/10.1161/CIRCULATIONAHA.112.091421.

12. Ruiz-Irastorza G, Garmendia M, Villar I, Egurbide MV, Aguirre C. Pulmonary hypertension in systemic lupus erythematosus: Prevalence, predictors and diagnostic strategy. Autoimmun Rev. 2013;12(3):410-5, http://dx.doi.org/ 10.1016/j.autrev.2012.07.010.

13. van 't Hof AWJ, Liem A, Suryapranata H, Hoorntje JC, de Boer MJ, Zijlstra F. Angiographic assessment of myocardial reperfusion in patients treated with primary angioplasty for acute myocardial infarction: Myocardial blush grade. Zwolle Myocardial Infarction Study Group. Circulation. 1998;97(23): 2302-6, http://dx.doi.org/10.1161/01.CIR.97.23.2302.

14. Wang ML, Beeckman-Wagner LA, Wolfe AL, Syamlal G, Petsonk EL. Lung-function impairment among US underground coal miners, 2005 to 2009: Geographic patterns and association with coal workers' pneumoconiosis. J Occup Environ Med. 2013;55(7):846-50, http://dx.doi.org/10.1097/ JOM.0b013e31828dc985.
15. Spiekerkoetter E, Fabel H, Hoeper MM. Effects of inhaled salbutamol in primary pulmonary hypertension. Eur Respir J. 2002;20(3):524-8, http://dx.doi.org/10.1183/09031936.02.0 2572001.

16. Steenhuis LH, Groen HJ, Koëter GH, van der Mark TW. Diffusion capacity and haemodynamics in primary and chronic thromboembolic pulmonary hypertension. Eur Respir J. 2000;16(2):276-81, http://dx.doi.org/10.1034/j.1399-30 03.2000.16b15.x.

17. Wang XR, Christiani DC. Respiratory symptoms and functional status in workers exposed to silica, asbestos, and coal mine dusts. J Occup Environ Med. 2000;42(11):1076-84, http://dx.doi.org/10.1097/00043764-200011000-00009.

18. Wang X, Yu IT, Wong TW, Yano E. Respiratory symptoms and pulmonary function in coal miners: Looking into the effects of simple pneumoconiosis. Am J Ind Med. 1999;35(2):124-31, http://dx.doi.org/10.1002/(SICI)1097-02 74(199902)35:2\%3C124::AID-AJIM3\%3E3.0.CO;2-M.

19. Fernie JM, Douglas AN, Lamb D, Ruckley VA. Right ventricular hypertrophy in a group of coalworkers. Thorax. 1983;38(6):436-42, http://dx.doi.org/10.1136/thx. 38.6.436.

This work is available in Open Access model and licensed under a Creative Commons Attribution-NonCommercial 3.0 Poland License - http://creativecommons.org/ licenses/by-nc/3.0/p1/deed.en. 